\title{
Fracture mechanics assessment of fatigue semi-elliptical cracks in butt-welded joints
}

\author{
Evaluación por mecánica de la fractura de grietas semielipticas por fatiga en \\ uniones soldadas a tope
}

\author{
Edgar Hernández Laguna ${ }^{1} \quad$ Nelson Arzola de la Peña ${ }^{1} \quad$ Oscar Araque de los Ríos*2
}

Received: February 8, 2017 Accepted: September 25, 2017

Recibido 8 de febrero de 2017, aceptado 25 de septiembre de 2017

\begin{abstract}
This work carries out a theoretical study about the influence that profile geometry of the weld seam joints has on fatigue life. It is considered that SMAW butt-welded joints, $6 \mathrm{~mm}$-A36 structural steel board, and the E6013 electrode. The influence of geometry is parametrized by the overweight weld and the radius of the weld toe. To do the latter, an arrangement of experiments were made into 3 levels for each factor. For the development of the current work some information obtained from experimental results was used (i.e., weld profile and mechanical properties). The geometry of one group of real weld seams is digitalized and simulated in the construction of 3D solid-models, while a superficial semi-elliptical crack is defined around the weld toe. By applying the Finite Element Method, analytical equations are obtained for the weld magnification factors $\left(\mathrm{M}_{\mathrm{k}}\right)$. As main results of this work stand out, on the first hand, the strong influence that slub has on the fatigue life, an excess thickness means a reduction in the life forecast to even $42 \%$ for the welded joint. Secondly, the different behavior of strength intensity factor around the crack edge, which makes the crack become longer and narrower. The analytical equations for $\mathrm{M}_{\mathrm{k}}$ can be utilized on life-management model for butt-welded joints.
\end{abstract}

Keywords: Butt-welded joint, fatigue, semi-elliptical crack, stress intensity factor, fracture mechanics, life assessment.

\section{RESUMEN}

En este trabajo se realiza un estudio teórico sobre la influencia que posee en la vida de fatiga la geometría del perfil del cordón de soldadura. Se considera una soldadura a tope utilizando SMAW, placas en acero estructural A36 de $6 \mathrm{~mm}$ de espesor y electrodo E6013. La influencia de la geometría es parametrizada por medio del sobreespesor del cordón y el radio del pie de soldadura, para ello se realiza un arreglo de experimento a tres niveles. Para el desarrollo del presente trabajo se utilizó cierta información proveniente de resultados experimentales (por ejemplo: perfil de soldadura y propiedades mecánicas). La geometría de un grupo de cordones de soldadura reales es digitalizada y emulada en la construcción de los modelos de sólido 3D, mientras que se define una grieta semielíptica superficial en el pie de la soldadura. Mediante el Método de los Elementos Finitos se obtienen ecuaciones analíticas para el factor de magnificación por soldadura $\left(M_{k}\right)$. Como resultados principales se destacan, en primer lugar, la marcada influencia que posee el sobreespesor del cordón en la vida de fatiga, un mayor sobreespesor significa una reducción en la predicción de vida de fatiga de hasta un $42 \%$ para la unión

1 Grupo de Investigación en Diseño Óptimo Multidisciplinario. Departamento de Ingeniería Mecánica y Mecatrónica. Universidad Nacional de Colombia. Bogotá, Colombia. E-mail: edhernandezl@unal.edu.co; narzola@unal.edu.co

2 Grupo de Investigación Desarrollo Tecnológico. Departamento de Ingeniería Mecánica. Universidad de Ibagué, Colombia. Email: oscar.araque@unibague.edu.co

Corresponding Author 
soldada considerada; y en segundo lugar la evolución diferente del factor de intensidad de esfuerzos en el perímetro del vértice de la grieta, lo cual provoca que la grieta durante su propagación estable se vuelva cada vez más alargada y estrecha. Las ecuaciones analíticas obtenidas para $M_{k}$ pueden ser utilizadas en modelos de gestión de vida para este tipo de unión soldada.

Palabras clave: Unión soldada a tope, fatiga, grieta semieliptica, factor de intensidad de esfuerzos, mecánica de la fractura, evaluación de vida.

\section{INTRODUCTION}

In butt-welded joints the geometrical profile and the fracto-mechanical material properties have a high influence on the resistance to fatigue. Certain geometrical factors, such as the radius of the weld toe $(\rho)$ and the over thickness weld (s), affect the initial period of fatigue cracks [1]: after the initiation period of the crack, its propagation speed will depend, in a big deal, on the fracto-mechanical properties of the material. In welded joints, mainly, these properties do not remain constant in all areas of the joint, due to the thermic gradient that is generated in the welding process. Therefore, three well-defined zones with different grain size and microstructure can be observed, as a result of the microstructural coalition, named the fusion zone (FZ), the heat affected zone (HAZ) and the base metal (BM) [2].

The surface cracks, which are generally present by fatigue of welded joints, are semi-elliptical in the radius of the weld toe. This geometry allows carrying out the crack behavior, by mathematical assessments, through Mechanical Fracture based on the stress distribution, deformation and displacements in front of the fracture through the stress intensity factor $(\mathrm{K})$ [3]; it is also possible to assess the crack propagation by fatigue in welded joints after using the empirical relation proposed by Paris and Erdogan [4]:

$$
\frac{d a}{d N}=C(\Delta K)^{m}=C(\beta \Delta \sigma \sqrt{\pi a})^{m}
$$

As it is obtained:

$$
\mathbf{N}=\int_{\mathbf{a}_{\mathrm{i}}}^{\mathbf{a}_{\mathrm{f}}} \frac{\mathbf{d a}}{\mathrm{C} \cdot(\boldsymbol{\beta} \Delta \sigma \sqrt{\pi \mathbf{a}})^{\mathbf{m}}}
$$

Where $\mathrm{da} / \mathrm{dN}$ is the crack growth per cycle; $\mathrm{C}$ and $\mathrm{m}$ are material constants for a specific stress ratio $\mathrm{R}$; $\Delta \sigma$ is the nominal stress range; $\beta$ is a dimensionless function that depends on the geometry of the component and the crack size; $\Delta \mathrm{K}$ is the stress intensity factor range; and a is the crack depth (the subindices $i$ and $f$ indicate the initial and final crack depth respectively). The fatigue strength in welded joints can be expressed as the quantity of necessary cycles for a semi-elliptical shape surface crack gets propagated through the thickness of the joint [5].

In welded joints stress fields at the crack are more complex to determine due to microstructural alterations, typical of welded joints because of cooling thermic cycle [6]. An equation to calculate $\mathrm{K}$ in semi-elliptical surface cracks has been developed by [7], describing a weight function through a surface crack on a plate and an edge crack in a semi-infinite plane. In [8] Maddox introduced a dimensionless factor $\mathrm{Mk}$, which allows estimating the influence of stress concentrations generated by the geometric profile of fillet welded joints over the stress intensity factor. This analysis is based on semielliptical surface cracks by fatigue located around the weld toe, where the $\mathrm{M}_{\mathrm{k}}$ factor is obtained by the relation of stress intensity factor estimated by the Finite Element Method and the nominal value of $\mathrm{K}$ (denominator of the equation), as shown in equation (3).

$$
M_{k}=\frac{K}{\sigma \sqrt{\pi a}}
$$

Where $\sigma$ is the nominal stress.

According to a review [9] to estimate the fatigue life on welded joints is common to assess the phase of stable propagation of cracks only. In comparison to the initiation phase cracks, the propagation is extensive. Likewise, the crack propagation allows assessing, as a whole, the fracto-mechanics and geometrical properties of welded joints, as well as, the behavior of different structural elements and cracks through weight/element analysis of finite functions [10-4]. The Finite Elements Method allows determining the obtained stresses expressing them as a polynomic equation (4). 


$$
\begin{aligned}
& \sigma_{\left(\frac{x}{a}\right)}=\sum_{j=0}^{n} \sigma_{j} \cdot\left(\frac{x}{a}\right)^{j} \\
& =\sigma_{0}+\sigma_{1}\left(\frac{x}{a}\right)+\sigma_{2}\left(\frac{x}{a}\right)^{2}+\cdots
\end{aligned}
$$

Where $\mathrm{K}$ can be expressed as shown in equation (5):

$$
K=\sqrt{\pi a} \cdot \sum_{j=0}^{n} \sigma_{j} \cdot f_{j}(a / t ; a / c ; \ldots)
$$

Where $\mathrm{x}$ is the distance front the crack tip; $\mathrm{a}$ is the crack depth; $\mathrm{c}$ is the semi-length of the crack and $\mathrm{t}$ is the thickness of the base plate.

In [12] the distribution of $\mathrm{K}$ at the crack tip was assessed for 27 semi-elliptical surface cracks located at the weld toe, which are subjected to eight types of main stresses throughout the analysis of finite elements utilizing a net of iso-parametric elements 20-Node in 3-D. However, as it relates to the analysis in the butt-welded joints did not take into account the influence of over thickness weld. On the other hand in [5] carried out a research which assessed a great set of geometrical parameters related to butt-welded joints and their influence on the crack propagation by fatigue. Throughout the Mechanics of Elastic Linear Fracture, the analysis of finite elements and superposition theories could estimate a mathematical model that can determine the fatigue resistance in butt-welded joints. There are several methods to get the $\mathrm{K}$ values in surface cracks, as it is shown on [13], where a majority of these methods rely on the analysis of the finite elements. The latter allows generating results of high precision, even though an efficient program is required to generate the best tetrahedral mesh based on the type of crack and applied environmental conditions. To be able to utilize the method of weight function is vital to know the crack geometries and the welded joint. For instance, in [13] state an equation (6) for the weight function for $\mathrm{K}$ in the following manner:

$$
\int_{\Gamma_{c}} \frac{1-v^{2}}{E} K_{I}^{(2)} K_{I}^{(1)} f_{\alpha}=\int_{\mathrm{A}_{c}} \sigma^{(2)} \frac{\partial u^{(1)}}{\partial x_{\alpha}} d A
$$

Where $\sigma$ is the normal stress applied in the crack plane; $u$ is the respective displacement; $E$ the elastic module and $\mathrm{v}$ is the Poisson relation for the material. The exponents (1) are known reference solutions, and (2) is for arbitrary loads that should be calculated.
The integral of the left side of (6) is in function of the perimeter of the crack $\Gamma c$ and the right side is in function of the surface are of crack Ac.

To estimate $\mathrm{K}$ values based on finite element analysis requires a fine tetrahedral mesh around the front of the crack or special tools that include the particularities of the stress in the tip of the crack. Because the conventional elements do not consider the stress-deformation variation in the crack as it is explained in [14]. One of the methods used to improve the quality of the results to better assess the singularity, without reaching the limit of all refining elements was developed by [15], which one central node is displaced at one side of the quadrilateral that holds the iso-parametric elements in an 8-noded manner, up to reaching a quarter node located in the crack. When the central node is located, one of the quadrilateral sides to a quarter of singularity even more precise results are obtained for $\mathrm{K}$. The estimation of elastic linear deformation on ANSYS is obtained from the SOLID 186 elements with 3-D and 20-noded brick, because they allow to state, in a precise manner, the range of stress from the resulting singularity by the displacement of central nodes on one of the quadrilateral side to a quarter of singularity, as it is expressed in [16]. In this work, a study was carried out about fatigue failures in buttwelded joints for a structural steel to carbon ASTM A36, by using the electric arc welding process with a coated electrode E6013; in which the influence of the joint geometry throughout the analysis of finite elements based on the propagation of semi-elliptical cracks by fatigue in the weld toe. As a result from the study, a set of mathematical models was obtained for the weld magnification factor $\left(\mathrm{M}_{\mathrm{k}}\right)$ for weldbutt joints, which it useful for the later analysis of tolerance to failure and the forecasting of fatigue life in the welded joints.

\section{MATERIALS AND METHODS}

An analysis that included three different levels for two geometrical factors: the radius of the weld toe and the excess thickness of the $\varrho$ and s weld bead, respectively. Table 1 shows the different geometrical combinations used. In order to determine the resistance to fatigue for the butt-welded joints through the SMAW process, the parametrized geometry that appears on Figure 1 was utilized. The latter was the result of metallography tests and analysis of digital 
images of geometrical profiles from several buttwelded joints by utilizing CAD software, as shown on Figure 2. The levels of the factors used in the current experimental arrangement match to common real values of weld overthickness and radius of the weld toe measured experimentally. The material of the joint is defined as base structural steel ASTM A36, thickness of $6 \mathrm{~mm}$, and elastic boundary of $262 \mathrm{MPa}$ and stress resistance of $434 \mathrm{MPa}$. On the other hand, the input material is coated electrode E6013, 1/8 inch diameter, and elastic boundary of $360 \mathrm{MPa}$ and stress resistance of $500 \mathrm{MPa}$.

Table 1. Geometric combinations.

\begin{tabular}{crr}
\hline $\begin{array}{c}\text { Treatment } \\
\text { number }\end{array}$ & $\rho[\mathrm{mm}]$ & $\mathrm{s}[\mathrm{mm}]$ \\
\hline 1 & 0.3 & 1 \\
2 & 0.3 & 2 \\
3 & 0.3 & 3 \\
4 & 0.6 & 1 \\
5 & 0.6 & 2 \\
6 & 0.6 & 3 \\
7 & 0.9 & 1 \\
8 & 0.9 & 2 \\
9 & 0.9 & 3 \\
\hline
\end{tabular}

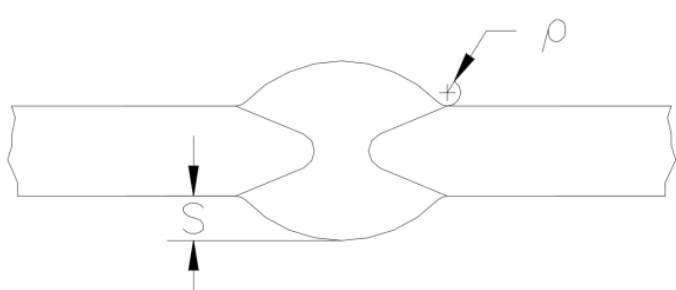

Figure 1. Parametrized geometrical factors for the analysis.

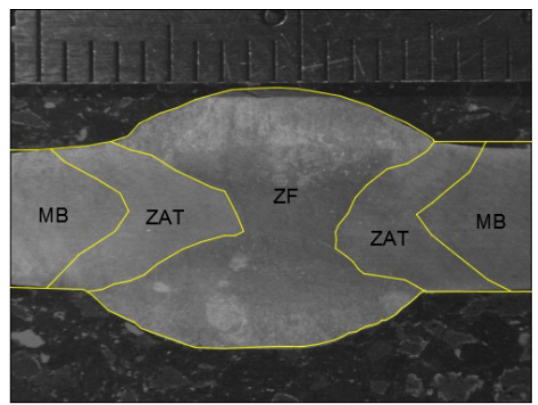

Figure 2. Geometric profile of referencefor the propagation simulations of crack (scale in mm).

For the welding procedure, the butt flat position, with a square joint design was used according to
[17], one voltage between $15-42 \mathrm{~V}$, and current between 85-140 A (direct current). The welding speed was between 2 and $3 \mathrm{~mm} / \mathrm{s}$. The applied passes changed regarding the size of the excess thickness in the following way: a pass of weld for $\mathrm{s}=1 \mathrm{~mm}$ and two welding passes for $\mathrm{s}=2$ and 3 $\mathrm{mm}$, respectively. The general geometry analysis is shown in Figure 3. The fundamental goal to obtain these joints via experiments was the later digitalization of the over thickness weld profile, so that the solid model of the joint would simulate the real geometry with high fidelity.

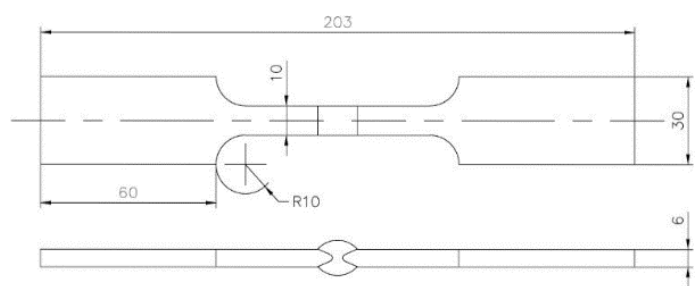

Figure 3. Sample geometry for the crack propagation simulations (units in $\mathrm{mm}$ ).

One of the tools utilized to assess the propagation of cracks by fatigue in the butt-welded joints is the Linear Elastic Fracture Mechanics though the the Finite Elements Method. In this research, the ANSYS 14.5 software was utilized, with which it is expected to reach representative values of the stress intensity factor, and from (3) to establish an analytical model based on the $\mathrm{M}_{\mathrm{k}}$ factor and the influence of the nine geometric combinations showed in Table 1 . To reach $\mathrm{M}_{\mathrm{k}}$ in function of the relation of crack size (a) and coat thickness (t). Through experimental results, the mechanical properties decided for three new materials in ANSYS's Workbench library, simulating three representative zones of butt-welded joints (FZ, HAZ and $\mathrm{BM}$ ) according to with results obtained by [18]. The simulated cracks always propagated through the HAZ zone.

A tetrahedral mesh was selected for three most adjacent zones to the crack, by the restriction of the fracture module. In other two adjacent zones, a mesh of automatic generation was utilized. Moreover, a convergence analysis was realized to estimate the quantity of necessary elements, in order to reach a value for the stress intensity factor, independent from the mesh density, in each of the crack sizes utilized in the analysis. In average, 819939 nodes and 553 
283 elements were used per each case. The contour conditions and the location of the semi-elliptical crack can be observed in Figure 4 for a load ratio $\mathrm{R}=0.05$, an axial cyclical load of $12120 \mathrm{~N}$ and fixed supports in the low end. For the size of the cracks, an aspect ratio was used $\mathrm{a} / 2 \mathrm{c}=0.25$, based on the experimental observations of analysis of the failures in butt-welded joints. The initial superficial semi-elliptical crack is located adjacent to the weld toe and in the middle plane of the plate. This site, close to the weld bead, has high local stresses and has been experimentally proven to be the site of highest probability of initiaton and spread of fatigue cracks [18].

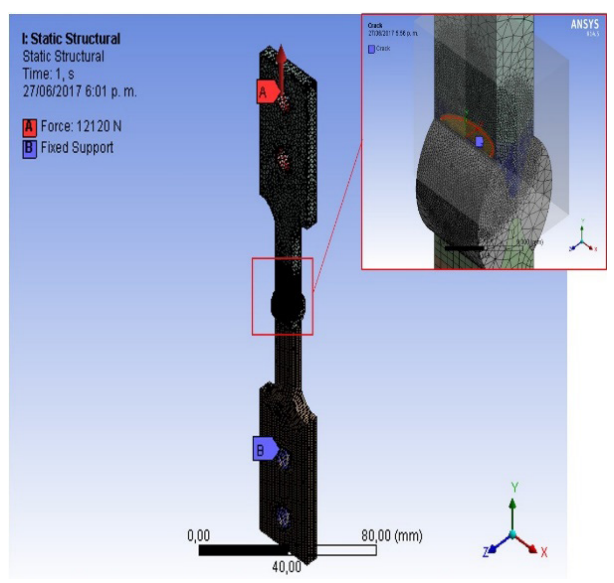

Figure 4. Contour conditions and semi-elliptical crack location for butt-welded joints subjected to uniaxial fatigue.

\section{DISCUSSION AND RESULTS}

The effect generated by the combination of the excess thickness $\mathrm{s}$ and the radius in the weld toe $\varrho$ in butt-welded joints can be observed in Figures 5 and 6 , for the combinations 1 and 3 from Table 1, respectively. Figure 5 shows a concentration stress in the weld toe of the over thickness weld, much less than that presented in Figure 6. It is important to highlight, that in these two combinations, the same value for $\varrho$ used. However, it is possible to observe clearly that, increasing the value of can make the concentration of stress greater. Due to the fact that in the over thickness weld appear the greatest stress concentration. As reference, this location was utilized as to the different sizes of semi-elliptical centered crack, in order to carry out the simulations of fatigue cracks propagation.
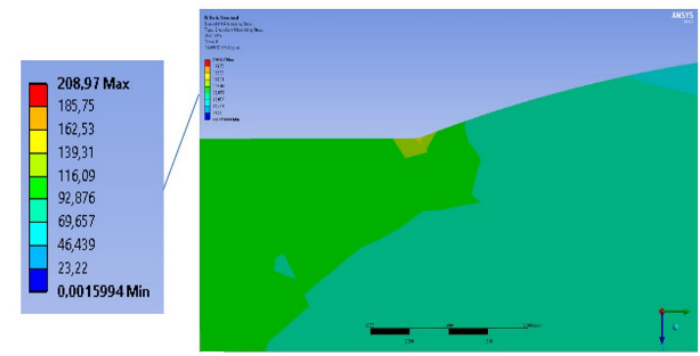

Figure 5. Cyclical equivalent stress for the geometric combination $1(\varrho=0.3 \mathrm{~mm} ; \mathrm{s}=1 \mathrm{~mm})$.
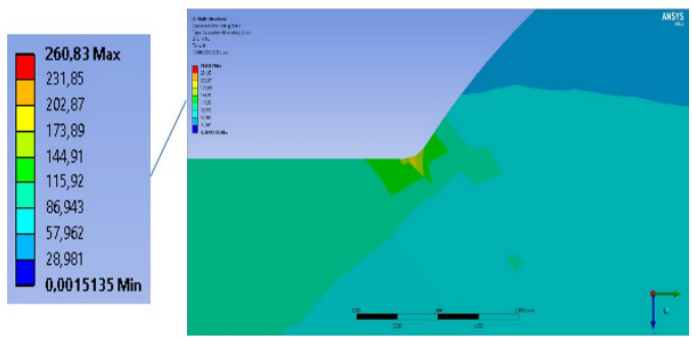

Figure 6. Cyclical equivalent stress for the geometric combination $3(\varrho=0.3 \mathrm{~mm} ; \mathrm{s}=3 \mathrm{~mm})$.

In Figure 7 the behavior of the magnification factor is presented in the crack of the weld toe, in function of the dimensionless depth of the crack, for the 9 treatments of Table 1 . The values have been obtained for the deepest point of the crack.

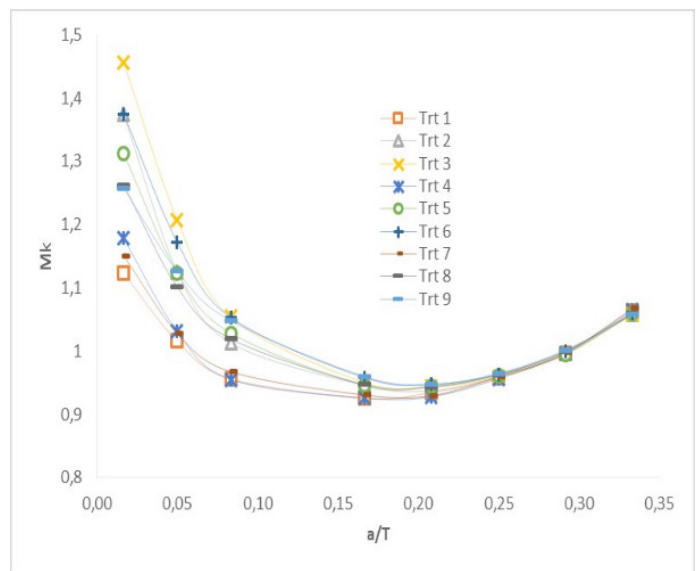

Figure 7. Dimensionless factor $\mathrm{M}_{\mathrm{k}}$ for semielliptical surface crack in butt-welded joints subjected to uniaxial fatigue. 
In the equation (7), the polynomial functions obtained analysis of regression are presented, for the curves in Figure 7 corresponding to the treatments 1, 3 and 5, respectively.

$$
M_{k}=\left\{\begin{array}{c}
131.23\left(\frac{a}{t}\right)^{4}-107.61\left(\frac{a}{t}\right)^{3}+35.765\left(\frac{a}{t}\right)^{2} \\
-5.2372\left(\frac{a}{t}\right)+1.2004\left(R^{2}=0,999\right) \text { for Trt. } 1 \\
-48.72\left(\frac{a}{t}\right)^{3}+38.36\left(\frac{a}{t}\right)^{2}-8.981\left(\frac{a}{t}\right) \\
+1.5807\left(R^{2}=0,990\right) \text { for Trt. } 3 \\
193.16\left(\frac{a}{t}\right)^{4}-165.25\left(\frac{a}{t}\right)^{3}+56.054\left(\frac{a}{t}\right)^{2} \\
-8.6131\left(\frac{a}{t}\right)+1.4389\left(R^{2}=0,999\right) \text { for Trt. } 5
\end{array}\right.
$$

Using the $\mathrm{M}_{\mathrm{k}}$ factor (see Figure 7) for the treatment number 5 , a comparison is made with the reported results by different authors, for butt-welded joints 3D [19], welded tubular welded structures [20] and the solution based on analysis by finite elements in $2 \mathrm{D}$ presented by [21], as shown in Figure 8.

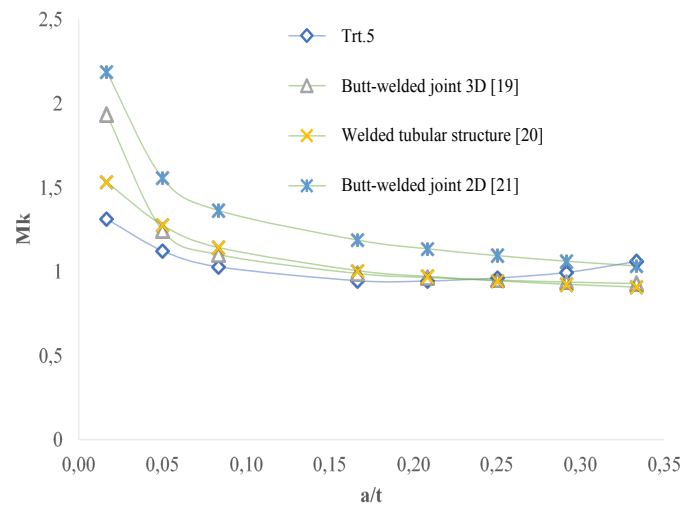

Figure 8. Comparison between different authors for the dimensionless $\mathrm{M}_{\mathrm{k}}$ factor for a semielliptical surfasse crack in butt-welded joints subjected to uniaxial fatigue.

To assess the differences between three models of reference in Figure 8, a percentage variation analysis was made in equation (8) a function of dimensionless crack size (a/t). The results are shown in Table 2. It is important to highlight that the minimum percentage of variation is $2.74 \%$ for the model of [19] and the maximum is $66.79 \%$ for the model of [21]. These last two results are in the range $\mathrm{a} / \mathrm{t}=0.017-0.050$.

$$
\% \operatorname{Var} M_{k}=\frac{\left|M_{k(T r t .5)}-M_{k[19-21]}\right|}{M_{k(T r t .5)}}
$$

Table 2. Variation percentage for values of $\mathrm{M}_{\mathrm{k}}$ in relation to treatment 5 .

\begin{tabular}{cccc}
\hline $\mathrm{a} / \mathrm{t}$ & $\mathrm{M}_{\mathrm{k}}(\%)^{*}$ & $\mathrm{M}_{\mathrm{k}}(\%)^{* *}$ & $\mathrm{M}_{\mathrm{k}}(\%)^{* * *}$ \\
\hline 0.017 & 47.53 & 16.76 & 66.79 \\
0.050 & 4.99 & 2.74 & 18.65 \\
0.083 & 16.03 & 12.84 & 3.99 \\
0.167 & 24.64 & 23.36 & 9.47 \\
0.208 & 26.43 & 25.98 & 13.42 \\
0.250 & 27.64 & 27.96 & 16.52 \\
0.292 & 28.53 & 29.54 & 19.06 \\
0.333 & 29.21 & 30.83 & 21.19 \\
\hline Where: *[19], **[20] and ***[21]
\end{tabular}

Another relevant result to assess the characterization of fatigue is the behavior of the SIF in function of the perimeter of the crack. In the Figures 9 and 10 the behavior of the SIF appears for the conditions or treatments 1 and 3 , in function of the position on the crack, as for semi-elliptical cracks, with initial aspect ratio $a / 2 c=0.25$. Likewise, $K_{I}$ behavior for eight sizes of crack shaped is shown. It can be seen that a progressive transition in $\mathrm{K}_{\mathrm{I}}$ behavior, for small cracks, the function is convex and the greatest value appears at the back of the crack, whereas for big cracks, the positions of the ends of the front of crack reach the maximum values for $\mathrm{K}_{\mathrm{I}}$.

This effect makes different rates of crack propagation along its base. Therefore, a semielliptical surface crack of type will be diminishing its aspect ratio, as it becomes larger.

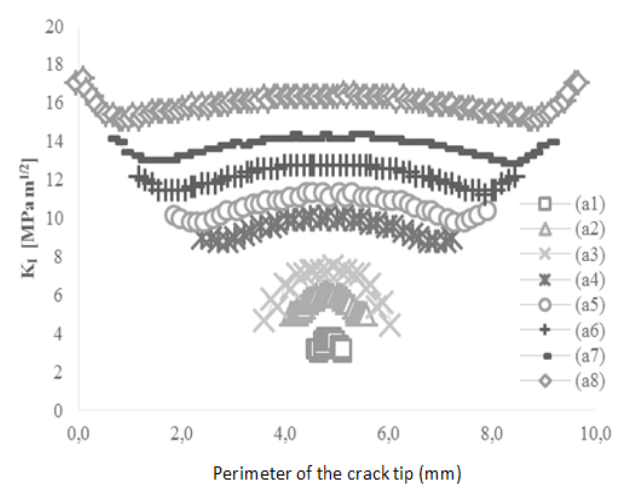

Figure 9. Variation of the stress intensity factor, in relation to the perimeter of the crack tip for the treatment 1 . 


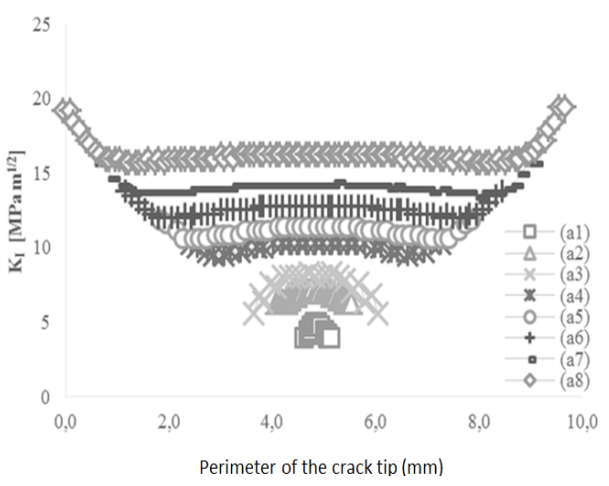

Figure 10. Variation of the stress intensity factor in relation to crack tip for the treatment 3 .

In Figure 11 the results of the stable crack propagation for the nine treatments from Table 1 are shown, obtained from (2). For $\mathrm{a}_{\mathrm{i}}=0.1 \mathrm{~mm} ; \mathrm{a}_{\mathrm{f}}=2 \mathrm{~mm}$; $\mathrm{C}=1.65 \times 10^{-11}[\mathrm{~m} /$ cycles] and $\mathrm{m}=3$, according to information supplied by [21]; finally, $\Delta \sigma=192 \mathrm{MPa}$. In Figure 11, it is possible to observe the generated grouping between the analysis treatments. In this case, the three treatments with major fatigue life (treatments 1, 4 and 7), have the over thickness weld size equal to $\mathrm{s}=1 \mathrm{~mm}$. On the other hand, the treatment 3 is the one resulting with less fatigue life, with over thickness weld size equal to $s=3$ $\mathrm{mm}$. A difference in fatigue life as high as $42 \%$ is predicted between the two over thickness used in the present research.

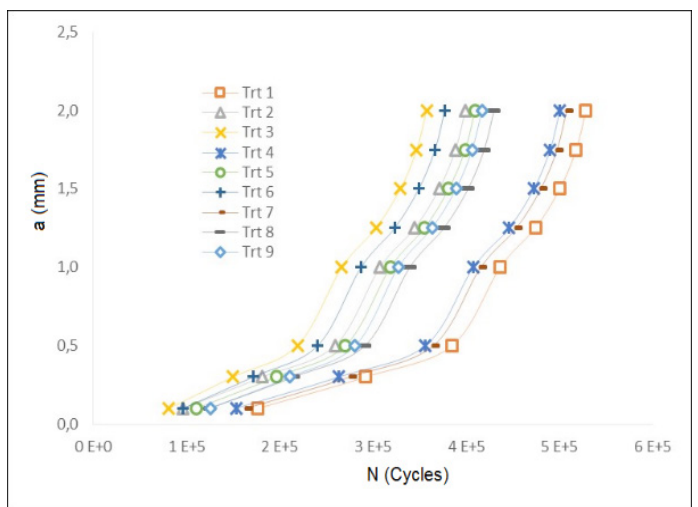

Figure 11. Curves of crack growth for butt-welded joints subjected to uniaxial fatigue.

\section{CONCLUSIONS}

The main contribution of the current research is the set of expressions for $\mathrm{M}_{\mathrm{k}}$ obtained as a function of the geometric parameters over thickness and weld toe radius in butt-welded joints. For this, a 3D finite element model is used, where the differentiation of the mechanical properties of the BM, HAZ and FZ zones is performed. Also, the present work model emulates the actual geometric configuration of butt-welded joints.

It can be concluded the influence of the excess thickness of the bead weld is more significant in the fatigue life of the welded joint, compared with the effect that makes the radius of the weld toe. Although both geometric factors have a significant influence and, therefore, should be considered in an analysis of life management. A major excess thickness, inside the variation range used in the current study, means a reduction in the prediction of fatigue life of up to $42 \%$ for the welded joint.

Analytical equations are obtained for $\mathrm{M}_{\mathrm{k}}$ that can be used in models of life management and tolerance to the damage of butt-welded joints, on similar type, in function of the geometric characteristics of the joints. When other authors' results [19-21] are contrasted, $\mathrm{M}_{\mathrm{k}}$ analytical functions result with low trend values in its behavior, for small cracks; then for $a / t>0.18$ begin to differ in a minimal manner. The differences observed between the current study and those from other authors might be fundamentally due to particularities, such as the profile of the buttwelded joints, employed in the different models.

Finally, the influence of the geometry of the bead weld, in the behavior of the stress intensity factor in the crack perimeter is analyzed. It is shown, in every model, that a semi-elliptical surface crack reduces its aspect ratio, as it increases its size, due to the different magnitudes that reaches the stress intensity factor, which leads to different propagation rates on the perimeter of the crack vertex. The results reached in the present research should be used carefully, until they can be experimentally proved with more results.

\section{ACKNOWLEDGMENTS}

The authors wish to thank the Dirección Nacional de Investigación de la Sede Bogotá - Universidad Nacional de Colombia and Universidad de Ibagué for the support offered in conducting this investigation. 


\section{REFERENCES}

[1] J. Schijve. "Fatigue of structures and materials". Dordrecht. Boston MA: Kluwer Academic. pp. 535-557. ISBN: 0-7923-7013-9.

[2] O.J. Araque y N. Arzola. "Estudio teórico experimental sobre el fenómeno de enfriamiento postsoldadura en una unión soldada cruciforme". Ingeniare. Rev. chil. ing. [online]. 2016. Vol. $24 \mathrm{~N}^{\circ} 2$ [citado 201701-31], pp.228-238. Disponible en: <http:// www.scielo.cl/scielo.php?script $=$ sci_ar ttext\&pid=S0718-3052016000200006 $\& \operatorname{lng}=e s \& n r m=i s o>$. ISSN: 0718 3305. http://dx.doi.org/10.4067/ S0718-33052016000200006.

[3] A. Hobbacher. "The use of fracture mechanics in the fatigue analysis of welded joints". Fracture and Fatigue of Welded Joints and Structures. pp. 91-112. 2011. ISBN 9781845695132. https://doi.org/10.1533/9780857092502.1.91

[4] P. Paris and F. Erdogan. "A Critical Analysis of Crack Propagation Laws". J. Basic Eng. Vol. $85 \mathrm{~N}^{\circ}$ 4, pp. 528. 1963.

[5] T. Ninh Nguyen. "A theoretical study of the effect of weld geometry parameters on fatigue crack propagation life". Eng. Fract. Mech. Vol. $51 \mathrm{~N}^{\circ}$ 1, pp. 1-18. 1995.

[6] Y. Lu. "Crack aspect development curves and fatigue life prediction for surface cracks at weld toes in the presence of residual stress". Int. J. Fatigue. Vol. 17 N 8, pp. 551-557. 1995.

[7] I. E. Kopsov. "Stress intensity factor solution for a semi-elliptical crack in an arbitrarily distributed stress field". Int. J. Fatigue. Vol. $14 \mathrm{~N}^{\circ}$ 6, pp. 399-402. Nov. 1992.

[8] S. J. Maddox. "An analysis of fatigue cracks in fillet welded joints". Int. J. Fract. Vol. 11 $\mathrm{N}^{\circ}$ 2, pp. 221-243. 1975.

[9] W. Fricke. "Fatigue analysis of welded joints: state of development". Marine Structures. Vol. 16 N$^{\circ} 3$, pp. 185-200. 2003. ISSN 0951-8339. http://dx.doi.org/10.1016/ S0951-8339(02)00075-8.

[10] M. D. Chapetti and L. F. Jaureguizahar. "Fatigue behavior prediction of welded joints by using an integrated fracture mechanics approach". Int. J. Fatigue. Vol. 43, pp. 43-53. 2012. ISSN: 0142-1123. https://doi. org/10.1016/j.ijfatigue.2012.02.004.
[11] U. Zerbst, R. A. Ainsworth, H. T. Beier, H. Pisarski, Z. L. Zhang, K. Nikbin, T. NitschkePagel, S. Münstermann, P. Kucharczyk, and D. Klingbeil. "Review on fracture and crack propagation in weldments - A fracture mechanics perspective". Eng. Fract. Mech. Vol. 132, pp. 200-276. 2014. ISSN: 0013-7944. https://doi.org/10.1016/j. engfracmech.2014.05.012.

[12] Y. Lu. "A practical procedure for evaluating SIFs along fronts of semi-elliptical surface cracks at weld toes in complex stress fields". Int. J. Fatigue. Vol. $18 \mathrm{~N}^{\circ} 2$, pp. 127-135. 1996.

[13] T. Mikkola. "Method for calculating stress intensity factors for surface cracks". Eng. Fract. Mech. Vol. 42 N5, pp. 713-730. 1992.

[14] E. Madenci and I. Guven. "Linear Structural Analysis". The Finite Element Method and Applications in Engineering Using ANSYS ${ }^{\circledR}$, Boston, MA: Springer US. pp. 313-454. 2015.

[15] R. Barsoum. "On the use of isoparametric finite elements in linear fracture mechanics". Int. J. Numer. Methods Eng. Vol. $10 \mathrm{~N}^{\circ} 1$, pp. 25-37. 1976.

[16] E. Madenci and I. Guven. "Linear Structural Analysis," in The Finite Element Method and Applications in Engineering Using ANSYS ${ }^{\circ}$, Boston, MA: Springer US. pp. 313-454. 2015.

[17] "Structural Welding Code Steel — Structural Welding Code- Steel 23rd Edition Supersedes AWS D1.1/D1.1M:2010”. 2015.

[18] E. Hernández. "Estudio teórico experimental de la resistencia a fatiga de uniones soldadas a tope considerando la influencia de la geometría de la unión y el ciclo térmico de enfriamiento". Thesis Universidad Nacional de Colombia, Colombia. 2017.

[19] S. T. Lie, H. S. Zhao and S. P. Vipin. "New weld toe magnification factors for semielliptical cracks in plate-to-plate butt-welded joints". Fatigue Fract. Eng. Mater. Struct. 2016. ISSN: 8756-758X. DOI: 10.1111/ ffe. 12485 .

[20] D. Bowness and M. M. K. Lee. "Fracture mechanics assessment of fatigue cracks in offshore tubular structures". HSE Books. pp. 41-56. 2002. ISBN: 978-0717623280. 
[21] B. and (BS) Standard. "BS 7910, (2005)." Guide to methods for assessing the acceptability of flaws in metallic structures". British Standards Institution, London. 2007.

[22] A. F. Hobbacher. "Recommendations for Fatigue Design of Welded Joints and Components". Cham: Springer International Publishing. pp. 143. 2016. ISBN: 978-3319237565. 